\title{
Lenf ödem ve kompleks boşaltıcı fizyoterapi
}

\section{Lymphedema and complex decongestive physiotherapy}

\section{Özge VERGILia}

Kırıkkale Üniversitesi Sağlık Bilimleri Fakültesi, Fizyoterapi ve Rehabilitasyon Bölümü, Kırıkkale, TÜRKiYE

\section{ÖZET}

Lenfatik sistemin yükünün artması ya da lenfatik transport kapasitesinin azalmasına bağlı olarak proteinden zengin sıvının hücre dışındaki boşluklara dolması sonucunda yumuşak dokularda ortaya çıkan şişme lenf ödem olarak adlandırılmaktadır. Lenf ödemin primer ve sekonder formları bulunmakta olup, hastanın yaşam kalitesini olumsuz yönde etkilemektedir. Bu derlemede lenf ödem ve tedavisinde kullanılan etkin bir tedavi yaklaşımı olan kompleks boşaltıcı fizyoterapi hakkında bilgi verilecektir.

Anahtar kelimeler: Fizyoterapi, Teknikleri, Lenf ödem, Manual terapi, Kompresyon bandajı.

\section{ABSTRACT}

Swelling of soft tissues due to collection of protein rich fluid into extracellular space caused by increased load of lymphatic system or decrease of lymphatic transport capacity is called lympedema. Both primary and secondary lymph edema effects the quality of patient lives. In this review we aimed to give information about lymph edema and its effective treatment approach; complex decongestive physiotherapy

Key words: Physiotheraphy, Techniques, Lymphedema, Manual therapy, Compression bandage. 


\section{Giriş}

Diğer ödem türlerinden farklı olarak lenf ödem bir semptom değil, lenfatik sistemin çalışma kapasitesindeki yetersizlikten kaynaklanan bir hastalıktır. Söz konusu hastalıkta lenfostaz sonucunda dokularda morfolojik ve fonksiyonel anlamda çeşitli değişiklikler meydana gelmekte olup, uygulanacak tedavinin başarısı patofizyoloji hakkında sahip olunan bilgiyle doğru orantılı olmaktadır [1].

Lenf ödem (LÖ), proteinden zengin sıvının hücre dışı boşluklarda birikmesi sonucunda yumuşak dokuların şişmesidir. Bu durum azalmış lenfatik transport kapasitesinden kaynaklanabileceği gibi, lenfatik sistemin yükünün artmış olması da aynı klinik tabloyla sonuçlanabilmektedir [1]. LÖ kronik, ilerleyici bir durum olup, şişen alanların hem ebat hem de ağırlık olarak artış göstermesi nedeniyle eklem hareketlerini ve mobiliteyi bozmakta, sıklıkla postüral bozukluklara ve ağrıya neden olarak bireyin günlük yaşam aktivitelerini yerine getirmesini zorlaştırmaktadır. Öyle ki sadece hafif düzeyde bir LÖ dahi vücut imajını bozarak fiziksel ve psikososyal fonksiyonda ve yaşam kalitesinde ciddi bozukluklara neden olabilmektedir [2].

LÖ primer ya da sekonder olarak sınıflandırılmaktadır. Primer LÖ lenfatik malformasyonun bir sonucu olup, kişinin doğumuyla birlikte ortaya çıkabileceği gibi yıllar sonra da görülebilmektedir. Sekonder LÖ ise cerrahi sırasında lenfatik damarların ya da nodların çıkartılması ya da hasar görmesi, radyasyon tedavisi, travma, yanık, infeksiyon ya da ödeme neden olan kronik böbrek yetmezliği, karaciğer yetmezliği ya da kronik venöz yetmezlik gibi lenfatik yükü artıran komorbid durumlara bağlı olarak lenfatik damarların aşırı derecede yüklenmesi gibi durumlara ikincil olarak gelişmektedir. Sekonder LÖ'nün en sık nedeni kanser tedavisinde kullanılan cerrahi tedaviler ve radyasyon tedavisidir. LÖ en sık ekstremiteleri etkilemekle birlikte baş, boyun bölgelerinde, gövde ve abdomende ve genital bölgede de görülebilmektedir [3].

LÖ'nün şiddeti genellikle "Uluslararası Lenf ödem Cemiyeti" nin yapmış olduğu evreleme sistemine göre belirlenir. Bu sisteme göre bireyin içinde bulunduğu LÖ evresi 0 ile 3 arasında değişmektedir. Sıfır, latent evre olup, bu evrede ekstremite risk altındadır. Lenfatik staz mevcuttur. LÖ'ye ait herhangi bir klinik bulgu söz konusu değildir, ancak birey intermitant ağrı, yorgunluk ve riskli ekstremitede ağırlık hissi deneyimleyebilmektedir. Evre 1'de ödem basınçla birlikte gode bırakmaktadır. Elevasyonla birlikte şişlik tamamen azalmaktadır. Klinik fibrozis varlığı söz konusu değildir ve evre 2'ye ilerleme süresi kişiden kişiye farklılık göstermektedir. Evre 2'de ödem gode bırakmamaktadır. Şişlik elevasyonla birlikte tamamen azalmamaktadır. Klinik fibrozis mevcuttur. Bu evredeki ödem gode bırakan ve bırakmayan ödemin kombinasyonu olabilmektedir (miks evre $1+2)$. Evre 3'de ise cilt kalınlaşmakta ve sertleşmektedir. Subkuten dokularda hipertrofi gelişmekte olup, deride papillomalar oluşmaktadır. Doku şişmekte, çıkıntı oluşturmakta ve deri katlantıları gelişmektedir. Bu durum üst ekstremitelerde daha az sıklıkla görülmektedir [2].
LÖ ilerleme gösterdikçe fibrozitler ve/veya adipozitler etkilenen bölgelere prolifere olmakta, bu da cildin ve cilt altı dokuların yapısında değişikliğe neden olarak bakteriyal ve fungal enfeksiyonlara olan yatkınlığı artırmaktadır. Sekonder LÖ’nün lenfatik sistemde meydana gelen ilk hasardan ne kadar süre sonra meydana geleceği kişiden kişiye farklılık göstermekte olup, postoperatif erken dönemde hemen görülebileceği gibi, aylar ya da yıllar sonra da görülebilmektedir. Söz konusu bu latent evrede lenf stazı bulunmakla birlikte, belirgin bir klinik şişlik yoktur. Bu dönemde LÖ gelişme riskini azaltmaya yönelik hazırlanmış olan rehberlere sağlanacak uyum, risk taşıyan bu hastalarda LÖ gelişmesini tetikleyecek durumlardan kaçınmak için son derece önemlidir [3].

LÖ'den yakınan hasta sayısı her geçen gün artmaktadır. Bunda rol oynayan iki temel faktör bulunmaktadır. Birincisi yaşlı nüfusun giderek artıyor olmasıdır. Yaşlanmayla birlikte lenf pompalarının gücü azalmakta, kalp yetmezliği, metabolik hastalıklar ve artropatiler gibi lenf ödem risk faktörleri ortaya çıkmaktadır. İkincisi ise malignansilerin tedavisindeki gelişmenin daha uzun remisyonlara neden olmasıdır, hatta daha fazla sayıda hastanın tedaviye cevap veriyor olmasıdır. Ancak, terapilerin yan etkisi olarak ekstremitelerde, baş bölgesinde ve genital bölgede LÖ görülmektedir. Kompleks boşaltıcı fizyoterapinin kullanımı da bu anlamda gittikçe yaygınlaşmakta olup, başarılı sonuçlar elde edilmektedir [1].

\section{Kompleks Boşaltıcı Fizyoterapi}

Kompleks boşaltıcı fizyoterapi (KBF) LÖ tedavisinde standart yaklaşım olarak kabul edilmektedir [2-4]. KBF'nin iki fazı bulunur. Birinci faz"yoğun faz" olarak da adlandırılmakla birlikte, bu fazdaki amaç ödemin azaltılmasıdır. İdeal olarak KBF'nin başlangıçtaki yoğun fazı maksimal hacim azalması ve doku yapısının normale dönmesi sağlanana kadar günlük olarak uygulanır [4]. Bu amaçla günlük olarak manual lenf drenajı (MLD) uygulaması yapılarak, ardından cilt bakımı ve kompresyon bandajı uygulanır. Hasta bu fazda self-bandaj uygulamasını da öğrenir [5-10]. KBF'nin "koruma fazı" olarak da adlandırılan ikinci fazına geçiş kriteri ise tedaviye alınan vücut bölümlerinin normal sınırlar içindeki ölçülere yaklaşmış olmasıdır. Bu aşamada kompresyon çorabı kullanımına geçilir. Kompresyon çorabının kişiye özel olması tercih edilir. Bu amaçla hastadan dikkatli bir biçimde ölçü alındıktan sonra çorabı sipariş edilir. Koruma fazındaki amaç "yoğun fazda" elde edilen kazanımların korunması ve/ veya artırılmasıdır. Bu fazda yine MLD'ye devam edilebilir. Buna kişinin MLD'ye olan ihtiyacına göre karar verilmekle birlikte, yine uygulama sıklığı ihtiyaca göre haftada bir ya da birkaç kez olabilir. Bu fazda hastanın ev programıyla takip edilmesi söz konusudur. KBF'nin içeriğini yukarıda adı geçmiş olduğu üzere bazı temel komponentler oluşturur. Bunlardan birincisi ortalama olarak altmış dakika süren ve lenfatik sistemi stimüle etmek amacıyla kullanılan özelleşmiş hafif bir manual terapi tekniği olan MLD dir. İkinci komponent, çok katlı ekstremite bandajı ya da kompresyon bandajı olarak da bilinen kısa gerimli kompresyon bandajı uygulaması olup, pompalanan ödem miktarını 
artırmak ve ekstremiteyi aşırı basınçtan korumak için sünger vb. bazı yumuşak malzemelerin üzerine uygulanabilmektedir. Üçüncü komponent egzersizdir. Bunlar, lenfatik pompalamayı artıran özellikte egzersizlerdir. Egzersiz sayesinde lenfatik pompalamanın niteliğinde ve niceliğinde artış sağlanabilmektedir. Dördüncü komponent etkilenen alanlara çok dikkatli bir biçimde uygulanan cilt bakımı olup, beşinci ve son komponent ise tedavi boyunca elde edilmiş olan kazanımların korunması amacıyla uygun kompresyon giysilerinin tatbik edilmesidir[4,11]. Baş, boyun, gövde bölgeleri ile genital bölge ise kompresyon uygulamanın oldukça zor olduğu bölgelerdir. Bu nedenle bu bölgelerdeki ödemin uzun süreli kontrol altında tutulması çok da kolay değildir. Tedaviden elde edilen kazanımların uzun vadeli olabilmesi için hastaya detaylı bir eğitimin verilmesi de çok önemlidir. Bu eğitimde risk azaltmaya yönelik yaklaşımlar, kişisel bakım, egzersizlerin ve self drenajın her gün düzenli olarak uygulanması ve kompresyon giysilerinin uygun şekilde kullanılması konularına yer verilmektedir [3,4,11-13].

\section{Manual Lenf Drenajı}

Manual lenf drenajı (MLD) olarak bilinen orijinal manual teknikler 1936 yılında Emil Vodder tarafından geliştirilmiştir. MLD'de kullanılan intermitant, hafif basınç içeren dört temel el temas biçimi, direkt olarak cilt üzerine uygulanarak çok küçük yüzeysel lenfatiklerde germe etkisi oluşturmakta, böylelikle lenfatik damar kontraksiyonunu ve etkilenen alandan olan lenf drenajını artırmaktadır. MLD’nin lenfolenfatik ya da lenfovenöz anastomozları stimüle ettiği gösterilmiştir [11,15]. Bununla birlikte MLD'nin, KBF'nin kompresyon komponentinin ya da diğer komponentlerinin tek başına uygulanmasıyla elde edilemeyecek düzeyde semptomlarda azalma sağladığı da yapılan çalışmalarla gösterilmiştir [16-21]. MLD ile ödemin kişide oluşturduğu ağırlık ve gerginlik gibi subjektif yakınmalar daha etkin bir biçimde tedavi edilebilmektedir [22]. MLD LÖ tedavisinde kendi başına da çok etkin bir tedavi modalitesi olmakla birlikte, ekstremitede volüm azaltılmasının sağlanması ve bunun devam ettirilmesi için kompresyon bandajlarıyla birlikte uygulanmasının daha olumlu sonuçlar açığa çıkartacağı görüşü literatürde yer alan çalışmaların sonuçlarıyla da desteklenmiştir [15,23-25]. Bununla birlikte baş, boyun bölgeleri, genital bölge gibi kompresyon uygulamasının zor olduğu bölgelerde ve palyatif bakım gibi kompresyonun tolere edilemeyeceği durumlarda MLD'nin tek başına da etkin bir şekilde kullanılabileceği de yapılan çalışmalarla gösterilmiştir [3,26].

MLD'de cilt üzerine ortalama otuz - kırk beş $\mathrm{mm} \mathrm{Hg}$ gibi düşük bir basınca denk gelecek şiddette ritmik germeler uygulanarak, lenf damarlarının daha sık kasılması ve lenfatik akımın normal işlev gören en yakın bölgedeki lenf sistemine doğru yönlendirilmesi sağlanır $[27,28]$. MLD'ye drenajın yönlendirileceği bölgelerdeki lenf nodlarının stimülasyonu ile başlanır. Stimülasyonu takiben etkilenen vücut bölgesinde birikmiş olan sıvının fonksiyonel olan bu lenf nodlarına doğru dekonjesyonu manual olarak sağlanır. Tedavi sırasında lenf nodu stimülasyonunun ve LÖ'lü bölgelerin dekonjesyonunun proksimalden distale doğru ilerleyecek şekilde yapılmasına dikkat edilir [13,27].
MLD'nin klinikteki en yaygın kullanımı kanser cerrahisi sonrasında gelişmekte olan LÖ'nün önlenmesi ve tedavi edilmesine yönelik olup [29-34], kronik venöz yetmezlikte venöz staz komplikasyonlarının önlenmesinde ve tedavi edilmesinde [35-39], ortopedik cerrahilerden ve ortopedik ve sportif yaralanmalardan sonra görülen ödemin tedavi edilmesinde [4043] de kullanılmaktadır.

\section{Kompresyon Bandajları ve Giysileri}

LÖ'nün başarılı bir şekilde tedavi edilmesinde kompresyonun önemi çok büyüktür. MLD'yi takiben LÖ'lü ekstremiteye, lenfatik drenajla ödemde elde edilen azalmayı devam ettirmek üzere, çok katlı kısa gerimli kompresyon bandajları uygulanır. Kompresyon bandajı interstisyel doku sıvısının basıncında ve lenf emiliminde artış oluşturarak, MLD ile temizlenmiş olan doku boşluklarının tekrar dolmasını önler [11]. Kısa gerimli kompresyon bandajlarıyla ekstremiteye rölatif olarak daha düşük bir istirahat basıncı uygulanır. Spor yaralanmaları vb. sonrasında uygulanan daha elastik olan uzun gerimli bandajlardan farklı olarak kompresyon bandajları, deri katlantıları arasında ve eklem çevresinde çok fazla sıkışmaz. Tam tersine ekstremite hareket ettiğinde ve kaslar aktif olarak kasıldığında kasların daha etkin bir biçimde kasılabilmesi için stabil bir destek yapısı oluşturur. Böylelikle lenfatik pompalama ve akış, venöz akış artar, kapiller filtrasyon azalır ve daha fazla ödem absorbsiyonu gerçekleşir $[11,44]$. Kompresyon giysileri de yine lenfatik akımı ve venöz dönüşü artırmanın yanında ilgili ekstremitenin düzgün şekillenmesini, hacim kontrolünü ve cilt bütünlüğünü sağlar, ekstremiteyi dışarıdan gelebilecek yaralanmalara karşı da korur [45]. Kompresyon bandajları ve/veya kompresyon giysilerinde uygulanmakta olan kompresyonun distalden proksimale doğru kademeli olarak azaltılacak şekilde ayarlanmasına dikkat edilir [46].

MLD ile elde edilen kazanımların devam ettirilmesinde kompresyonun önemi çok büyüktür. Literatürde yer alan çalışmaların sonuçları da bu görüşü destekler niteliktedir [17,24]. Bu nedenle özellikle tedavinin ilerleyen dönemlerinde kompresyona mutlaka devam edilmesi gerektiği konusunda hastaların bilgilendirilmesi gerekmektedir. KBF almakta olan hastanın gerek tedavi ve gerekse takibi sürecinde LÖ'de elde edilmiş olan azalmaların korunmasında en önemli unsurun kompresyon uygulamalarına hastanın ne denli uyum gösterdiği ve bandaj ve/veya çorap kullanımını ne ölçüde doğru ve düzenli bir şekilde yerine getirmekte olduğu yapılan çalışmaların sonuçlarıyla da desteklenmiştir [12,17,25,47].

Ancak, kompresyon bandajlarının ve giysilerinin kullanımındaki en önemli problem, hasta toleransının ve dolayısıyla uyumunun düşük olmasıdır. Bunda söz konusu materyallerin oluşturduğu görüntünün hoş olmaması, hastaya rahatsızlık verebiliyor olması, giyilmesinin zor olması ve pahalı olması gibi faktörler rol oynamaktadır [48]. Bu noktada hastanın en erken dönemden itibaren kompresyonun önemi ve gerekliliği konusunda uygun şekilde bilgilendirilmesinde ve böylelikle tedaviye olan uyumunun artırılmasında tedaviyi yürütmekte olan fizyoterapiste çok büyük görev düşmektedir. 


\section{Cilt Bakımı}

LÖ'nün patofizyolojisinde belirtildiği üzere proteinden zengin sıvının hücre dışı boşluklarda birikmesiyle dokuda proliferasyon meydana gelmekte, bu da "lenfostatik fibrozis" olarak adlandırılan, ilgili bölgedeki konnektif dokunun yapısında ilerleyici bir sertleşme oluşmasına neden olmaktadır. Dolayısıyla LÖ'nün optimal düzeyde tedavi edilebilimesi için prolifere olmuş bu dokuların yumuşatılması gerekmektedir [49].

LÖ hastası etkilenmiş olan ekstremitesini / ekstremitelerini günde iki kez herhangi bir kesik, abrazyon, kızarıklık, Isı artışı ya da artmış şişlik gibi enfeksiyon varlığı açısından kontrol etmelidir. LÖ hastalarının immün fonksiyonlarında bozukluk olması nedeniyle, infeksiyonlardan kaçınmak için etkilenmiş olan ekstremitelerinde cilt bakımının çok dikkatli biçimde uygulanması gereklidir. Bu doğrultuda cilt bütünlüğünün korunması ve ciltteki sorunların dikkatlice yönetilmesi büyük öneme sahiptir [50,51]. Cildin yumuşak ve esnek olması cildin kırılganlığını azaltacağı için bakterilerin bütünlüğü bozulmuş olan bölgelerden penetre olarak infeksiyona yol açma ihtimali de azalacaktır [52,53]. Bu amaçla pH'sı nötr olan doğal sabunlar ile etkilenmiş olan ekstremitenin / ekstremitelerin günlük olarak yıkanıp kurulanması, esans içermeyen nemlendiricilerle nemlendirilmesi gereklidir. Yıkama ve nemlendirme hareketleri esnasında tercihen MLD'de uygulanan, distalden proksimale doğru ilerleme prensibine dikkat edilmelidir [50,51]. Cildin enfeksiyonlara karşı önemli bir bariyer olduğunu unutmadan, ciltteki gerginliği ve kuruluğu giderme ana amaçları doğrultusunda cilt bakımına gereken önem daima verilmeli ve bu konudaki hasta eğitimine de gerekli özen gösterilmelidir.

\section{Terapatik Egzersiz}

Egzersiz kanserin önlenmesinde ve tedavi edilmesinde önemli bir komponenttir [54,55]. Egzersiz tedavisi ile kanser hastalarında yorgunluk azalmakta, kuvvet ve esneklik artmakta, vücut imajı ve yaşam kalitesinde iyileşme elde edilmektedir [56]. Egzersizin kanser hastalarındaki bu genel etkilerinin yanında, özellikle kanser tedavisine yönelik cerrahiler sonrasında gelişme ihtimali yüksek olan LÖ'nün önlenmesinde ve tedavi edilmesinde de rolü büyüktür. Meme kanseriyle ilişkili LÖ gelişme riski cerrahiyi takip eden iki yıl içerisinde ortalama \%26 olarak bildirilmiştir [57]. LÖ'nün hastanın gerek genel sağlık durumunu ve gerekse yaşam kalitesini ne denli olumsuz biçimde etkilediği göz önünde bulundurulduğunda, egzersiz tedavisinin önemi bir kez daha ön plana çıkmaktadır.

Egzersiz fizyolojik olarak LÖ'den etkilenmiş olan ekstremitedeki venöz ve lenfatik geri dönüşü artıran muskuloskeletal pompa mekanizmasını aktive eder. Bununla birlikte üst gövde egzersizlerinin lenf damarlarına ait sempatik sinir sistemi aktivitesini sıfırladığı ve böylelikle LÖ ile uzun süreli mücadelede yarar sağladığı da ileri sürülmektedir [58].

LÖ'de rezistif egzersizlerin kullanımına yönelik literatürde yer alan çalışmalar daha çok meme kanseri cerrahisi geçirmiş olan hastalara yöneliktir [59-65]. Söz konusu bu çalışmalarda rezistif egzersiz programlarının hastaların üst ekstremitelerinde LÖ başlangıcı ve/veya eksaserbasyonuna yönelik yalnızca minimal risk taşıdığına, bu egzersiz modunun LÖ hastalarında kas gücünü artırmak için güvenle kullanılabileceğine dair oldukça güçlü kanıtlar ileri sürülmüştür [56]. Literatürde aerobik egzersizlerle kombine biçimde uygulanan rezistif egzersizlerin LÖ hastalarındaki etkinliğini değerlendiren çalışmalar da yer almakta olup [66-68], bu çalışmaların sonucunda ilgili egzersiz programlarının söz konusu hasta popülasyonunda güvenle kullanılabileceği gösterilmiştir [56]. Ancak, egzersizlerin şiddetinin, aşırı direncin ultrafiltrasyonu artırarak ödemde artışa neden olabileceği dikkate alınarak ayarlanması gerekmekte olup [69], LÖ'sü bulunan ya da LÖ gelişme riski bulunan hastaların, konusunda uzman fizyoterapistler tarafından hazırlanmış olan egzersiz programlarına katıımı teşvik edilmelidir [70].

\section{Çıkar çatışması ve Finansman Beyanı}

Bu çalışmada çıkar çatışması ve finansman destek alındığı beyan edilmemiştir.

\section{Kaynaklar}

1. Foldi E. The treatment of lymphedema. Cancer 1998; 83: 2833-4.

2. International Society of Lymphology. The diagnosis and treatment of peripheral lymphedema. 2009 Consensus Document of the International Society of Lymphology. Lymphology 2009; 42: 51-60.

3. Poage E, Singer M, Armer J, Poundall M, Shellabarger MJ. Demystifying lymphedema: Development of the lymphedema putting evidence into practice card. Clin J Oncol Nurs 2008; 12: 951-64.

4. Foldi M, Foldi E, Kubik S. Textbook of Lymphology: For Physicians and Lymphedema Therapists. San Francisco, CA: Urban \& Fischer; 2006.

5. Goodman CC, Fuller KS. Pathology: implications for the physical therapist. Philadelphia: W.B. Saunders Co, 2008.

6. Cheville AL, McGarvey, Petrek JA, Russo SA, Tayler ME, Thiadens SR. Lymphedema management. Semin Radiat Oncol 2003; 13: 290-301.

7. Casley-Smith,'Other techniques: compression pumps and devices, and heating', Proceedings of the conference'The lymphatic system, lymphoedema and its physical therapy. Australia, 1990; 132-139.

8. Ward RS. Role of physical therapists in the treatment of lymphedema. The American Physical Therapy Association 2009.

9. National Lymphedema Network Position Paper: Training of Lymphedema Therapists. 2013.

10. Foldi $M$, Strosenreuther R. Foundations of manual lymph drainage. Germany: Elsevier Mosby, 2005.

11. Foldi M, Foldi E, Kubik S. Textbook of lymphology. Munich, Germany: Elsevier; 2003.

12. Boris $M$, Weindorf $S$, Lasinkski S. Persistence of lymphedema reduction after noninvasive complex lymphedema therapy. Oncology 1997; 11: 99-110.

13. 13.Ko DSC, Lerner R, Klose G, et al. Effective treatment of lymphedema of the extremities. Arch Surg 1998; 133: 452-8. 
14. Badger CM, Peacock JL, Mortimer PS. A randomized, controlled, parallel-group clinical trial comparing multilayer bandaging followed by hosiery versus hosiery alone in the treatment of patients with lymphedema of the limb. Cancer 2000; 88: 2832-7.

15. Devoogdt N, Van Kampen M, Geraerts I, et al. Different physical treatment modalities for lymphoedema developing after axillary lymph node dissection for breast cancer: a review. Eur J Obstet Gynecol Reprod Biol 2009; 149: 3-9.

16. Hamner JB, Fleming MD. Lymphedema therapy reduces the volume of edema and pain in patients with breast cancer. Ann Surg Oncol 2007; 14: 1904-1908.

17. Kim S, Park Y. Effects of complex decongestive physiotherapy on the oedema and the quality of life of lower unilateral lymphoedema following treatment for gynecological cancer. Eur J Cancer Care 2009; 17: 463-8.

18. .Karadibak D, Yavuzsen T, Saydam S. Prospective trial of intensive decongestive physiotherapy for upper extremity lymphedema. J Surg Oncol 2008; 97: 572-577.

19. Kim SJ, Yi CH, Kwon OY. Effect of complex decongestive therapy on edema and the quality of life in breast cancer patients with unilateral leymphedema. Lymphology 2007; 40: 143-151.

20. Mondry TE, Riffenburgh RH, Johnstone PAS. Prospective trial of complete decongestive therapy for upper extremity lymphedema after breast cancer therapy. Cancer J 2004; 10: 42-48.

21. O'Neill J, Beatus J. The effects of complete decongestive physical therapy treatment on edema reduction, quality of life, and functional ability of persons with upper extremity lymphedema. J Womens Health Phys Ther 2006; 30: 5-10.

22. McCallin $M$, Johnston J, Bassett $\mathrm{S}$. How effective are physiotherapy techniques to treat established secondary lymphoedema following surgery for cancer? A critical analysis of the literature. N Z J Physiol 2005; 33: 101-112.

23. Karadibak D, Ufuk YS, Serdar S, et al. The comparison of two different physiotherapy methods in treatment of lymphedema after breast surgery. Breast Cancer Res Treat 2005; 93: 49-54.

24. Vignes S, Porcher R, Champagne A, et al. Predictive factors of response to intensive decongestive physiotherapy in upper limb lymphedema after breast cancer treatment: a cohort study. Breast Cancer Res Treat 2006; 98: 1-6.

25. Vignes S, Porcher R, Arrault M, et al. Long-term management of breast cancer-related lymphedema after intensive decongestive physiotherapy. Breast Cancer Res Treat 2007; 101: 285-290.

26. Lymphoedema Framework. Best practice for the management of lymphoedema: an international consensus. London: MEP Ltd; 2006. Available at: http://www.woundsinternational.com/pdf/ content_175.pdf [accessed February 27, 2015].

27. Cheville AL. Current and future trends in lymphedema management: implications for women's health. Phys Med Rehabil Clin N Am 2007; 18: 539-53.
28. Moseley AL, Carati CJ, Piller NB. A systematic review of common conservative therapies for arm lymphoedema secondary to breast cancer treatment. Ann Oncol 2007; 18: 639-46.

29. Andersen L, Højris I, Erlandsen M, Andersen J. Treatment of breast-cancerrelated lymphedema with or without manual lymphatic drainage-a randomized study. Acta Oncol 2000; 39: 399-405.

30. Devoogdt N, Christiaens MR, Geraerts I, Truijen S, Smeets A, Leunen $K$, Neven P, Van Kampen M. Effect of manual lymph drainage in addition to guidelines and exercise therapy on arm lymphoedema related to breast cancer: randomised controlled trial. BMJ 2011; 343: d5326.

31. Johansson K, Lie E, Ekdahl C, Lindfeldt J. A randomized study comparing manual lymph drainage with sequential pneumatic compression for treatment of postoperative arm lymphedema. Lymphology 1998; 31: 56-64.

32. Johansson K, Albertsson M, Ingvar C, Ekdahl C. Effects of compression bandaging with or without manual lymph drainage treatment in patients with postoperative arm lymphedema. Lymphology 1999; 32: 103-110.

33. Bakar Y, Akbayrak T. Kompleks boşaltıcı fizyoterapinin alt ekstremite lenf ödemi üzerine etkisi: pilot çalışma. Fizyoterapi Rehabilitasyon 2005; 16: 95-101.

34. Liao S-F, Li S-H, Huang H-Y. The efficacy of complex decongestive physiotherapy [CDP] and predictive factors of response to CDP in lower limb lymphedema [LLL] after pelvic cancer treatment. Gynecologic Oncology 2012; 712-5.

35. Molski P, Kruczynski J, Molski A, Molski S. Manual lymphatic drainage improves the quality of life in patients with chronic venous disease:arandomized controlled trial. Archieves of Medical Science $2013 ; 452-8$.

36. Bakar Y, Öztürk A, Çalısal M.A, Ertürk K, Dağlar B. Complete decongestive physiotherapy for older people with chronic venous insufficiency. Topics in Geriatric Rehabilitation 2010; 26: 164-70.

37. Criso'stomo R.S, Costa D.S.A, Martins C.L.B, Fernandes T.I.S, Armada-da-Silva P. Influence of manual lymphatic drainage on health-related quality of life and symptoms of chronic venous insufficiency: A randomized controlled trial. Archives of Physical Medicine and Rehabilitation 2015; 96: 283-91.

38. Criso'stomo R.S, Candeias M.S, Ribeiro A.M.M, Martins C.L.B, Armada-da-Silva P.A. Manual lymphatic drainage in chronic venous disease: A duplex ultrasound study. Phlebology 2014; 29: 667-76.

39. Molski P, Ossowski R, Hagner W, Molski S. Patients with venous disease benefit from manual lymphatic drainage. International Angiology 2009; 28: 151-5.

40. Ebert J.R, Joss B, Jardine B, Wood D.J. Randomized trial investigating the efficacy of manual lymphatic drainage to improve early outcome after total knee arthroplasty. Archives of Physical Medicine and Rehabilitation 2013; 94: 2103-11. 
41. Haren K, Backman C, Wiberg M. Effect of manual lymph drainage as described by Vodder on oedema of the hand after fracture of the distal radius: A prospective clinical study. Scand J Plast Reconstr Surg Hand Surg 2000; 34: 367-72.

42. Weiss JM. Treatment of leg edema and wounds in a patient with severe musculoskeletal injuries. Phys Ther 1998; 78: 1104-13.

43. Eisenhart AW, Gaeta TJ, Yens DP. Osteopathic manipulative treatment in the emergency department for patients with acute ankle sprains. J Am Osteopath Assoc 2003; 103: 417-21.

44. Partsch H, Flour M, Smith PC. Indications for compression therapy in venous and lymphatic disease consensus based on experimental data and scientific evidence. Under the auspices of the IUP. Int Angiol 2008; 27: 193-219.

45. Cheville AL. Current and future trends in lymphedema management: implications for women's health. Phys Med Rehabl Clin Am 2007; 18: 539-53.

46. Moseley AL, Carati CJ, Piller NB. A systematic review of common conservative treatments for arm lympoedema secondary to breast cancer treatment. Ann Oncol 2007; 18: 639-46.

47. Johnstone PA, Hawkins K, Hood S. Role of patient adherence in maintenance of results after manipulative therapy for lymphedema. J Soc Integr Oncol 2006; 4: 125-9.

48. Harris SR, Hugi MR, Olivotto IA, Levine M. Clinical practice guidelines for the care and treatment of breast cancer. 11. Lymphedema. CMAJ 2001; 164: 191-9.

49. Best Practice for the Management of Lymphoedema: an international consensus. English language edition. London: MEP Ltd, 2006: 53-54.

50. Bakar Y, Berdici B, Şahin N, Pala Ö.O. Meme kanseri ile ilişkili lenf ödem ve tedavisi. J. Breast Health 2014; 10: 6-14.

51. Lasinski B.B. Decongestive therapy for treatment of lymphedema. Seminars in Oncology Nursing 2013; 29: 20-27.

52. International Society of Lymphology. The diagnosis and treatment of peripheral lymphedema. 2009 Consensus document of the International Society of Lymphology. Lymphology 2009; 42: 51-60.

53. Lymphoedema Framework. Best practice for the management of lymphoedema: an international consensus. London: MEP Ltd; 2006.

54. Doyle C, Kushi LH, Byers T, et al. Nutrition and physical activity during and after cancer treatment: an American Cancer Society guide for informed choices. CA Cancer J Clin 2006; 56: 323-53.

55. World Cancer Research Fund / American Institute for Cancer Research. Food, nutrition, physical activity and the prevention of cancer: a global perspective. Washington, DC: World Cancer Research Fund / American Institute for Cancer Research; 2007.
56. Kwan ML, Cohn JC, Armer JM, et al. Exercise in patients with lymphedema: a systematic review of the contemporary literature. J Cancer Surviv 2011; 5: 320-36.

57. Erickson VS, Pearson ML, Ganz PA, et al. Arm edema in breast cancer patients. J Natl Cancer Inst 2001; 93: 96-111.

58. McKenzie DC, Kalda AL. Effect of upper extremity exercise on secondary lymphedema in breast cancer patients: a pilot study. J Clin Oncol 2003; 21: 463-6.

59. Schmitz KH, Ahmed RL, Troxel A. Weight lifting in women with breast-cancer-related lymphedema. N Engl J Med 2009; 361: 664-73.

60. Schmitz KH, Ahmed RL, Troxel AB. Weight lifting for women at risk for breast cancer-related lymphedema: a randomized trial. JAMA 2010; 304: 2699-705.

61. Ahmed RL, Thomas W, Yee D. Randomized controlled trial of weight training and lymphedema in breast cancer survivors. J Clin Oncol 2006; 24: 2765-72.

62. Sagen A, Karesen R. Physical activity for the affected limb and arm lymphedema after breast cancer surgery. A prospective, randomized controlled trial with two years follow-up. Acta Oncol 2009; 48: 1102-10.

63. Kilbreath SL, Refshauge KM, Beith JM. Progressive resistance training and stretching following surgery for breast cancer: study protocol for a randomised controlled trial. BMC Cancer 2006; 6: 273.

64. Irdesel J, Celikatas SK. Effectiveness of exercise and compression garments in the treatment of breast cancer related lymphedema. Turk J Phys Med Rehab 2007; 53: 16-21.

65. Sander AP. A safe and effective upper extremity resistive exercise program for woman post breast cancer treatment. Rehabil Oncol 2008; 26: 3-10.

66. Courneya KS, Segal RJ, Mackey JR. Effects of aerobic and resistance exercise in breast cancer patients receiving adjuvant chemotherapy: a multicenter randomized controlled trial. J Clin Oncol 2007; 25: 4396-404.

67. Hayes SC, Reul-Hirche H, Turner J. Exercise and secondary lymphedema: safety, potential benefits, and research issues. Med Sci Sports Exerc 2009; 41: 483-9.

68. Portela ALM, Santaella CLC, Gomez CC, et al. Feasibility of an exercise program for Puerto Rican women who are breast cancer survivors. Rehabil Oncol 2008; 26: 20-31. consensus. English language edition. London: MEP Ltd, 2006: 47.

69. de Godoy JM, de Godoy Mde F. Godoy\& Godoy technique in the treatment of lymphedema for under-privileged populations. Int J Med Sci 2010; 7: 68-71.

70. National Lymphedema Network, Position Paper. The diagnosis and treatment of lymphedema 2011. 